\title{
Frequency and Socio-demographic Characteristics of Patients presented with Ovarian Tumour at a tertiary care hospital
}

\author{
Zakaria $\mathrm{RE}^{1}$, Dewan $\mathrm{F}^{2}$, Yusuf $\mathrm{A}^{3}$, Rahman $\mathrm{M}^{4}$, Hauque $\mathrm{M}^{5}$
}

\begin{abstract}
Background: Ovarian tumour causes great morbidity and mortality. Objective: The purpose of the present study was to analyze the different presentation of ovarian tumours to see the frequency and clinicdemographic characteristics of ovarian tumour. Methodology: This cross sectional study was conducted in the Department of Gynaecology \& Obstetrics, Shaheed Suhrawardy Medical College, Dhaka during the period from January to June 2013 for a period of six months. Patient admitted in Department of Obstetrics \& Gynaecology ward in Shaheed Suhrawardy Medical College Hospital with provisional diagnosis of ovarian tumour were selected as study population. Proper permission was taken from the ethical committee of Shaheed Suhrawardy Medical College Hospital for this study. All the patients were informed about the various aspects of the study. Their verbal consents were taken. Women of all ages with ovarian tumour were included in this study. Women with all other tumour except ovarian tumour were excluded from this study. A thorough history variably collected, clinical examination and investigations was carried out. The result of benign and malignant ovarian neoplasms in regard to age parity, physical sign, vaginal examination, laparotomy findings, together with their macroscopic findings are tabulated separately. Histopathological examination was done by senior pathologists of ShSMCH. Result: A total 50 cases of ovarian tumour had been studied of which 26 (52\%) were benign and $24(49 \%)$ were malignant ovarian tumours which were confirmed by histopathological examination $(\mathrm{P}>0.05) .28 \%$ and $12 \%$ patient with benign ovarian tumour were in age group of $18-34$ years and $35-45$ years and $14 \%$ patient with malignant ovarian tumour in age group $>45$ years $(p>0.05) .32 \%$ patient with benign ovarian tumours came from poor socio economics condition and $20 \%$ from middle class, $28 \%$ patient with malignant ovarian tumour came from poor and $16 \%$ from middle class family. Out of 50 cases of ovarian tumour, 39 were married and 11 were unmarried. $51 \%$ patients did not use any contraceptives and $31 \%$ oral contraceptives $(\mathrm{P}<0.05)$. No family history was found in $92 \%$ patients. $16 \%$ patients with benign tumours were unmarried. Conclusion: In conclusion ovarian tumour are mostly benign of which middle age group are most commonly reported. [J Shaheed Suhrawardy Med Coll, December 2014;6(2):76-78]
\end{abstract}

Keywords: ovarian tumour, Demographic characteristics, socioeconomic condition

Received: 1 December 2013; Reviewed: 19 February 2014; Accepted: 7 June 2014

\section{Introduction}

Tumours of the ovary are the common form of neopalsia in women ${ }^{1}$. Ovarian cancer account for $6 \%$ of all cancers in the female and is the fifth most common form cancer in women. Incidence of ovarian turnour amongst the gynecological admission varies $1-3 \%$, about $75 \%$ of these tumours are benign and $25 \%$ are malignant ${ }^{2}$. Atetiology of ovarian tumour is not exactly known, but a number of predisposing risk factors have been identified. These are reduced family size, later age of first conception, family history, a possible link with the use of fertility drug, pt. who have had irradiation to the ovaries for menorrhagia, pt. of higher socio-economic status, white women are at higher risk, blood group A, a personal or family history of ovarian cancer or endometrial,

1. Dr. Rooh E Zakaria Assistant Professor, Department of Obstetrics \& Gynaecology, Shaheed Suhrawardy Medical College, Dhaka

2. Prof. Dr. Farhana Dewan, Professor \& Head, Department of Obstetrics \& Gynaecology, Shaheed Suhrawardy Medical College, Dhaka

3. Dr. Md. Abdullah Yusuf, Assistant Professor, Department of Microbiology, National Institute of Neurosciences \& Hospital, Dhaka

4. Dr. Mamunur Rahman, Assistant Professor, Department of Surgery, Shaheed Suhrawardy Medical College Dhaka

5. Dr. Mojammel Hauque, Assistant Professor, Department of Surgery, Shaheed Suhrawardy Medical College Dhaka

\section{Correspondence}

Dr. Rooh E Zakaria, Assistant Professor, Department of Gynaecology \& Obstetrics, Shaheed Suhrawardy Medical College, Sher-E-Bangla Nagar, Dhaka-1207, Bangladesh; Email: roohezakaria@gmail.com; Cell no.: +8801727701665

Conflict of interest: None

Authors Contribution: REZ, FD, MR \& MH were involved in protocol development to collection as well as the study works. Data analysis, interpretation \& manuscript writing were performed by REZ and MAY. All the authors have revised the manuscript. 
colon, or breast ${ }^{3}$. Three hereditary ovarian cancer syndromes place a small number of women at significantly increased risk breast ovarian cancer syndrome, Site specific ovarian cancer syndrome, Lynch II syndrome, which consists of non polyposis Colorectal cancer, endometrial cancer, ovarian cancer, cancer of upper gastrointestinal tract and possibly cancer of the kidney pelvis and ureter ${ }^{4}$. Transvaginal sonography can help in the early detection and characterization of small ovarian tumour. Further characterization may be aided by color Doppler blood flow studies. However, as a single screening test, transvaginal sonography has not made a significant impact on survival ${ }^{5}$. It is important to know nature of the tumour before surgery, especially of young patient, wishes to have children, and conservation treatment could be possible. The purpose of the present study was to analyze the different presentation of ovarian tumours to see the frequency and clinic-demographic characteristics of ovarian tumour.

\section{Methodology}

This cross sectional study was conducted in the Department of Gynaecology \& Obstetrics, Shaheed Suhrawardy Medical College, Dhaka during the period from January to June 2013 for a period of six months. Patient admitted in obs \& Gynae ward in SHSMCH with provisional diagnosis of ovarian tumour were selcetd as study population. Proper permission was taken from the ethical committee of Shaheed Suhrawardy Medical College Dhaka for this study. All the patients were informed about the various aspects of the study. Their verbal consents were taken. Women of all ages with ovarian tumour. Women with all other tumour except ovarian tumour. A thorough history variably collected, clinical examination and investigations was carried out. Data recorded in a pre-designed data collection sheet (Appendix-1). The result of benign and malignant ovarian neoplasms in regard to age parity, physical sign, vaginal examination, laparotomy findings, together with their macroscopic findings are tabulated separately. Histopathological examination was done by senior pathologists of Shaheed Suhrawardy Medical College Dhaka. Collected data compiled and chi-square and validity test done using computer based software and analyzed by statistical package for social science (SPSS).

\section{Results}

A total number of 9 Upazila in Sirajgonj District and another 9 A total number of 50 cases of ovarian tumour had been studied of which 26 were benign and 24 were malignant ovarian tumours which were confirmed by histopathological examination.

Table 1: Nature of tumour $(n=50)$

\begin{tabular}{lcccc}
\hline Tumour & Frequency & Percentage & $\mathbf{X}^{\mathbf{2}}$ & P value \\
\hline Benign & 26 & 52 & & \\
Malignant & 24 & 48 & 0.08 & 0.777 \\
Total & $\mathbf{5 0}$ & $\mathbf{1 0 0 . 0}$ & & \\
\hline
\end{tabular}

The $52 \%$ patients were benign ovarian tumour and $49 \%$ patients were malignant ovarian tumour. The difference was not statically significant $(\mathrm{P}>0.05)$ (Table 1$)$

Table 2: Age distribution of the patient $(n=50)$

\begin{tabular}{lcccc}
\hline Age Group & Benign & Malignant & $\mathbf{X}^{\mathbf{2}}$ & P value \\
\hline$<18$ years & $3(6 \%)$ & $2(4 \%)$ & & \\
18-34 years & $14(28 \%)$ & $7(14 \%)$ & 0.080 & 0.777 \\
35-45 years & $6(12 \%)$ & $8(16 \%)$ & & \\
$>45$ years & $3(6 \%)$ & $7(14 \%)$ & & \\
\hline
\end{tabular}

It has been observed that $28 \%$ and $12 \%$ patient with benign ovarian tumour were in age group of 18-34 years and 35-45 years and $14 \%$ patient with malignant ovarian tumour in age group $>45$ years. The difference was not statistically significant $\mathrm{P}>0.05$ (Table 2).

Table 3: Socio economic status of the study population $(n=50)$

\begin{tabular}{lcccc}
\hline Socio-economic status & Benign & Malignant & $\mathbf{X}^{2}$ & P value \\
\hline Poor & $16(32 \%)$ & $14(28 \%)$ & & \\
Middleclass & $10(10 \%)$ & $8(16 \%)$ & 0.080 & 0.777 \\
Affluent & 26 & $2(4 \%)$ & & \\
\hline
\end{tabular}

The result showed that $32 \%$ patient with benign ovarian tumours came from poor socio economics condition and $20 \%$ from middle class, $28 \%$ patient with malignant ovarian tumour came from poor and $16 \%$ from middle class family. Only a few came from affluent family. The difference was not statistically significant (Table 3 ).

Table 4: Contraceptive use $(n=39)$

\begin{tabular}{lcccc}
\hline Contraceptive Use & Frequency & Percentage & $\mathbf{X}^{2}$ & P value \\
\hline None & 20 & 51.28 & & \\
Oral pill & 12 & 30.77 & 14.727 & 0.002 \\
Injectable & 4 & 10.25 & & \\
Tubectomy & 3 & 7.69 & & \\
\hline
\end{tabular}

Out of 50 cases of ovarian tumour, 39 were married and 11 were unmarried. Table IV shows that $51 \%$ patients did not use any contraceptives and $31 \%$ oral contraceptives. The difference was statistically significant $(\mathrm{P}<0.05)$ (Table 4).

\section{Table 5: Family History of Ovarian Tumor $(n=50)$}

\begin{tabular}{lcccc}
\hline Family History & Frequency & Percentage & $\mathbf{X}^{\mathbf{2}}$ & P value \\
\hline Present & 4 & 8 & & \\
Absent & 45 & 92 & 34.306 & 0.001 \\
\hline
\end{tabular}

It had been found that $92 \%$ patients had no family history and $8 \%$ patients had family history. The difference was statistically significant (Table 5).

Table 6: Distribution of marital status and parity $(n=50)$

\begin{tabular}{|c|c|c|c|c|}
\hline $\begin{array}{l}\text { Marital } \\
\text { status }\end{array}$ & Frequency & Percentage & Malignant $X^{2}$ & P value \\
\hline Unmarried & & & & \\
\hline Marrie & $39 c^{\circ}$ & & $21(42 \%) 12.703$ & 0.001 \\
\hline \multirow[t]{2}{*}{ Parity } & Null & 10( & $19(38 \%)$ & \\
\hline & Multipara & $8(16 \%)$ & $2(4 \%)$ & \\
\hline
\end{tabular}


A total number of $16 \%$ patients with benign tumours were unmarried. Among married women 20\% nullipara and $16 \%$ multipara with Bening tumour and $36 \%$ nullipara and $4 \%$ multipara tumour. The difference was statistically significant (Table 6).

\section{Discussion}

Snake bite is another major case of mortality and A sonographic morphology score (SMS) based on 4 morphologic characteristics of the mass (wall thickness, inner wall structure, characteristics of septae and echogenicity) allowed to differentiate benign from malignant ovarian masses with reasonable accuracy. The positive predictive value (PPV) of this system was lowered by obviously benign but nonetheless high scoring masses such as benign cystic teratomas, fibro thecoma and less frequently endometriomas ${ }^{7}$. Over the last few years, new diagnostic techniques have made a significant contribution of the diagnostic of adenexal masses and in selecting the best surgical treatment. The modality of the treatment varies according to the type of tumour and the benign malignant nature of the mass ${ }^{8}$. Considering that the lifetime risk of developing an ovarian tumour is around 5$7 \%$, diagnostic means are needed which permit accurate lassification of these ovarian. Unfortunately the available diagnostic modalities do not allow distinction of benign ovarian tumours from malignant tumours. In the majority of cases this is only established by histological analysis of the surgical specimen ${ }^{8}$. Whenever patient experiences any sign symptoms of ovarian tumour, or a patient found to have a pelvic mass, must be evaluated timely and in cost effective manner that is tailored to a realistic list of possible diagnosis ${ }^{9-18}$.

This study was carried out on 50 cases of ovarian neoplasm to find out the different types of ovarian neoplasm and determine the frequency of each type and also to compare between benign and malignant ovarian tumour. The age ranged 10 to 70 years, with highest incidence between 20 and 44 years. The average age incidence in this study was 38.2 years which was comparable to Tasmin 18 . In this study $28 \%$ and $12 \%$ patient with benign ovarian tumours were in age group of 18-34 years and 35-45 years and $14 \%$ patient with malignant ovarian tumours in age group $>45$ years. The current literature showed that $85 \%$ of ovarian tumours were benign in women during their reproductive years ${ }^{13}$. Of these benign ovarian masses, $66 \%$ occur in women aged 20 to 44 years. The chance of a primary ovarian being malignant, therefore, in a woman less than 45 years of age was less than one in 1514

Oral contraception use decreases the risk of ovarian tumour by $50 \%$ dependimg on the duration of use ${ }^{17}$. In this study, $51 \%$ patients did not use any contraceptives and $31 \%$ used oral contraceptives, which was similar to the findings by Tasmin $^{18}$ and Biswas ${ }^{19}$. A study ${ }^{13}$ of 924 women in New York City demonstrated that use of an oral contraceptive was associated with a decreased risk of benign ovarian tumours, with the greatest reduction occurring in women who used them for more than two years. One study showed an overall $40 \%$ risk reduction of ovarian cancer in women aged 20 to 24 who used oral contraceptives. After four years of oral contraceptive use, the risk of ovarian cancer decreased by $50 \%$, and after 7 years $60 \%$ to $80 \%$ reduction in disease was noted.

This study shows, family history of ovarian neoplasm was present in 4 percent case, which is similar to the present study. In this study most of the patient did not give history of such type of disease in her close or first degree relatives, only a few give history of colonic carcinoma and few with metastatic had a history of breast carcinoma and possibly gall bladder malignancy. In present study vaginal examination was done in 39 cases, rest 11 was unmarried. Uterus was normal in size in $54 \%$ cases. Mass separated from the uterus of $57 \%$ cases benign tumour. Mass could not be separated from the uterus in $14 \%$ cases of malignant ovarian tumour. These findings were comparable with Biswas ${ }^{19}$, in this study uterus was normal size in $60 \%$ cases. The mass could not be separated from the uterus in $22.86 \%$ cases.

\section{Conclusion}

Benign ovarian tumours are more prevalent in the reproductive age group; whereas prevalence of malignancy is more in the two extremes of life before puberty and after menopause. Pregnancy with ovarian tumour and sudden severe pain with ovarian tumour within reproductive age group are benign.

\section{References}

1. Md. Monirul Islam and Kimmiteru Sado. Development of hazard maps of Bangladesh using NOAA-AVHRR images with GIS, Hydrological sciences Journal-des Science Hydrologiques, 45(3) June 2000

2. Bangla Pedia, National encyclopedia of Bangladesh, 2006.

3. IRIN, a service of the UN office for the Humanitarian Affairs, 23 April 2012.

4. Ridwanur Rahman, M. Abul Faiz, Shahjada Selim, Bayzidur Rahman, Ariful Basher, Alison Jones, Catherine d' Este, Moazzem Hossain, Ziaul Islam, Habib Ahmed, Abul Hasnat Milton.

5. Baqui AH, Black RE, Arifeen SE, Hill K, Mitra SN, al Sabir A. Causes of childhood deaths in Bangladesh: results of a nation-wid verbal authopsy study. Dhaka: International Centre for Diarrhea Disease Research, Bangladesh, 1997. 43 p. (ICDDR, B special publication no.60).

6. MT Miah, AA Hoque, BK Tarafer, MKH Patwary, RR Khan, SMEJ Kabir. Epidemiology, clinical profile and outcome of patients of snake bite in Mymensingh medical college hospital. Journal of Bangladesh College of Physicians and Surgeons. Vol. 27, No.2, May 2009.

7. Pandey DP. Epidemology of snake bites bases on hospital survey in Chitwan and Nawalparasi districts, Nepal. Journal of Nepal Health Research council Vol. 4 No.2 October

8. Jamaiah I, Rohela M, roshalina R and Undan RC. Prevalence of snake bites in kangar district hospital, Perlis, west Malaysia: A retrospective study (January 1999-December 2000), Southeast Asian J Trop Med Public Health.

9. Chippaux JP (1998) snakebites: appraisal of the global situation bulletin of the world health organization 76: 515-524.

10. Flood control room DGHS, Bangladesh, September 10, 2007. 